\title{
PENGEMBANGAN LEMBAR KERJA SISWA MATERI SPLDV BERBASIS KONTEKSTUAL BERBANTUAN SOFTWARE GEOGEBRA UNTUK SISWA KELAS VIII SMP
}

\author{
Dyah Hayu Kumarawati', Erlina Prihatnani² \\ 1Pendidikan Matematika, Universitas Kristen Satya Wacana, 202014089@student.uksw.edu \\ 2Pendidikan Matematika, Universitas Kristen Satya Wacana, erlina.prihatnani@gmail.com
}

\section{INFO ARTIKEL}

Riwayat Artikel:

Diterima: 21-04-2018

Disetujui: 30-04-2018

\section{Kata Kunci:}

SPLDV

Kontektual

Geogebra

ADDIE

\begin{abstract}
ABSTRAK
Abstrak: Penelitian ini bertujuan untuk mengembangkan LKS berbasis kontekstual berbantuan geogebra yang valid, praktis dan efektif. Penelitian ini menggunakan model pengembangan ADDIE dan telah dinyatakan valid dari aspek materi dan media pembelajaran dengan persentase berturut-turut 92,59\% dan 92,80\%, termasuk kategori sangat baik. Media ini telah diujicobakan kepada siswa kelas VIII SMP PGRI Banyubiru dan menghasilkan indeks kepraktisan penggunaan sebesar 75\%, masuk kategori praktis. Uji pair t-test dengan taraf signifikan $\alpha=0,05$ menghasilkan signifikan mendekati nol kurang dari 0,05 dengan rata-rata posttest lebih tinggi daripada pretest. Berdasarkan ketiga hasil uji tersebut maka dapat disimpulkan bahwa media ini valid, praktis, dan efektif.
\end{abstract}

\begin{abstract}
This study aims to develop a Geogebra based, contextual, practical and effective contextual-based LKS. This research uses ADDIE development model and it has been stated valid from material aspect and instructional media with percentage of 92,59\% and 92,80\%, including very good category. This media has been tested to students of class VIII SMP PGRI Banyubiru and produce the practicality of the use index of $75 \%$, entered the practical category. T-test pair with significant level $\alpha=0.05$ yields significantly close to zero less than 0.05 with posttest average higher than pretest. Based on the three test results it can be concluded that the media is valid, practical, and effective.
\end{abstract}

\section{A. LATAR BELAKANG}

Matematika merupakan ilmu universal yang mendasari perkembangan teknologi modern yang mempunyai peran penting dalam berbagai disiplin ilmu, dan mengembangkan daya pikir manusia. Mata pelajaran matematika perlu diberikan kepada semua peserta didik mulai dari sekolah dasar untuk membekali peserta didik dengan kemampuan berpikir logis, analitis, sistematis, kritis, dan kreatif, serta kemampuan bekerjasama (Depdiknas, 2006: 387). Dalam praktik pendidikan matematika, konstruktivisme juga sangat berpengaruh. Banyak cara belajar mengajar di sekolah yang didasarkan pada teori konstruktivisme, seperti cara belajar yang menekankan peranan siswa dalam proses pembelajaran sedangkan guru lebih berperan sebagai fasilitator yang membantu keaktifan siswa tersebut dalam pembentukan pengetahuannya (Suparno, 1996: 12).

Guru sebagai fasilitator dapat membantu agar proses belajar siswa berjalan dengan baik. Keaktifan ada pada siswa yang belajar dan bukan pada guru yang mengajar. Guru dapat menyediakan atau memberikan kegiatan-kegiatan yang merangsang keingintahuan siswa dan membantu mereka untuk mengekspresikan gagasan dan mengkomunikasikan ide ilmiah mereka (Suparno, 1996: 66). Agar peran dan tugas guru sebagai fasilitator tersebut dapat berjalan dengan optimal, guru perlu menciptakan media pembelajaran yang dapat digunakan untuk mendukung proses belajar mengajar. Media pembelajaran tersebut salah satunya adalah Lembar Kerja Siswa (LKS).

LKS sebagai salah satu bentuk media berlangsungnya proses belajar mengajar haruslah memenuhi persyaratan dan asas- asas agar LKS tersebut dapat digunakan secara efektif. Penyusunan LKS harus memperhatikan adanya perbedaan individual, bahwa antara siswa satu dengan yang lainnya tidaklah sama, baik dari segi pengetahuan maupun pengalaman belajarnya. Penyusunan LKS juga harus memperhatikan bahwa LKS harus dapat menyediakan ruangan yang cukup untuk memberi keleluasaan pada siswa untuk menuliskan jawaban. Perlu diperhatikan juga bahwa LKS harus menekankan pada proses untuk menemukan konsep-konsep (Darmodjo dan Kaligis, 1992:41- 46).

Untuk membantu siswa dalam menemukan konsepkonsep pembelajaran, guru harus menggunakan metode pembelajaran yang sesuai. Dalam LKS harus terdapat petunjuk-petunjuk yang bertujuan membimbing siswa untuk menemukan suatu konsep dan prinsip umum. 
Siswa didorong untuk berfikir sendiri, menganalisis sendiri, sehingga dapat menemukan konsep dan prinsip umum tersebut berdasarkan bahan atau data yang telah disediakan dalam LKS. Metode pembelajaran yang dirasa sesuai untuk mengembangkan lembar kerja siswa tersebut adalah metode penemuan terbimbing.

Masalahnya adalah masih terbatasnya Lembar Kerja Siswa yang disusun dengan tujuan untuk memfasilitasi siswa dalam pembelajaran. Contohnya LKS tentang SPLDV. Beberapa Lembar Kerja Siswa justru berisi ringkasan materi, contoh soal, dan evaluasi sehingga siswa tidak dapat menemukan sendiri konsepkonsep yang berkaitan dengan materi yang sedang dipelajari. Oleh karena itu, dilakukan penyusunan Lembar Kerja Siswa berbasis kontekstual yang mengajak siswa berpikir konstruktif, mampu membawa siswa pada kegiatan pembelajaran yang menarik, menyenangkan, sekaligus menantang siswa untuk berpikir dan menalar.

Wijayanti (2006: 4) menjabarkan salah satu syarat didaktik dalam penyusunan LKS adalah memiliki variasi stimulus melalui berbagai media dan kegiatan siswa sesuai dengan ciri kurikulum. Lembar Kerja Siswa hendaknya diiringi dengan perkembangan teknologi agar sesuai dan sejalan dengan tuntutan zaman. Sejalan dengan hal tersebut, Hidayah (2008: 7) menjelaskan bahwa LKS merupakan stimulus atau bimbingan guru dalam pembelajaran yang akan disajikan secara tertulis sehingga dalam penulisannya perlu memperhatikan kriteria media grafis sebagai media visual untuk menarik perhatian peserta didik. Adapun isi pesan LKS harus memperhatikan unsur-unsur penulisan media grafis, hirarki materi (matematika) dan pemilihan pertanyaanpertanyaan sebagai stimulus yang efisien dan efektif.

Salah satu materi yang diajarkan dalam matematika adalah Sistem Persamaan Linear Dua Variabel (SPLDV). Banyak permasalahan-permasalahan dalam kehidupan sehari-hari yang memerlukan pemahaman konsep SPLDV dalam pemecahannya. Dengan menguasai konsep SPLDV, siswa akan memiliki kemampuan memperoleh, mengelola, dan memanfaatkan informasi untuk dapat menyelesaikan masalah dalam kehidupanya sehari-hari. Selain itu materi SPLDV menjadi materi pra syarat beberapa materi selanjutnya seperti sistem persamaan linear tiga variabel, sistem persamaan kuadrat, dan program linear.

Dalam SPLDV, terdapat metode-metode untuk menentukan himpunan penyelesaian, salah satunya dengan metode grafik. Kebanyakan dari siswa mengalami kesulitan saat menggambar grafik, untuk itu perlu dilakukan penyusunan lembar kerja siswa berbantuan software yang dapat digunakan untuk membantu siswa dalam menggambar grafik. Selain itu, diperlukan software yang dapat membantu siswa untuk mengecek jawaban mereka dengan mudah. Salah satu software yang dapat digunakan untuk membantu penyusunan Lembar Kerja Siswa tersebut adalah Software Geogebra.
Menurut David Wess (Chandra Budhiawan, 2012: 20), Geogebra memungkinkan siswa untuk aktif dalam membangun pemahaman konsep. Program ini memungkinkan visualisasi sederhana dari konsep yang rumit dan membantu meningkatkan pemahaman siswa tentang konsep yang sedang dipelajari. Lebih lanjut Syahroni (2015) menyatakan bahwa Geogebra dapat memvisualisasikan benda-benda geometri dengan desain dan ukuran yang tepat dan menarik untuk siswa menemukan suatu konsep baru.

Dari uraian di atas, peneliti memandang perlu dikembangkannya LKS berbasis kontekstual berbantuan software Geogebra. Untuk itu, peneliti mengadakan penelitian dengan judul "Pengembangan Lembar Kerja Siswa Materi SPLDV Berbasis Kontekstual Berbantuan Software Geogebra untuk Siswa Kelas VIII".

Lembar Kerja Siswa ini akan menuntun siswa untuk dapat menemukan cara dan langkah- langkah untuk menyelesaikan persoalan matematika secara konstruktif. Dengan menggunakan LKS ini diharapkan siswa benar-benar aktif dan mandiri sehingga dapat lebih memahami dan mengingat lebih lama terkait materi yang dipelajari. Penggunaan LKS ini diharapkan dapat memberikan kesempatan penuh kepada siswa untuk mengungkapkan kemampuan dan keterampilan untuk berbuat sendiri dalam mengembangkan proses berpikirnya melalui mencari, menebak, bahkan menalar.

\section{B. METODE PENELITIAN}

\section{Jenis Penelitian}

Penelitian ini telah disusun menggunakan Research and Development (R\&D). Penelitian pengembangan adalah metode penelitian yang digunakan untuk menghasilkan produk tertentu dan menguji keefektifan produk tersebut (Sugiyono, 2014: 297). Produk yang dihasilkan dalam penelitian ini berupa Lembar Kerja Siswa pada materi Sistem Persamaan Linier Dua Variabel (SPLDV) untuk siswa kelas VIII. Penelitian ini menggunakan model pengembangan untuk media pembelajaran yang mengacu pada jenis pengembangan model ADDIE.

\section{Tempat dan Waktu Penelitian}

Penelitian ini dilaksanakan di SMP PGRI Banyubiru semester II tahun 2017/2018. Penelitian ini dimulai sejak bulan Maret hingga bulan Mei 2018 dengan penggunaan LKS untuk pembelajaran SPLDV untuk siswa kelas VIII.

\section{Teknik Pengumpulan Data}

Teknik pengumpulan data yang digunakan berupa angket validasi ahli materi dan ahli media, angket kepraktisan dan tes untuk mengukur hasil belajar siswa dengan menggunakan Lembar Kerja Siswa Berbasis Kontekstual Berbantuan Software Geogebra. 


\section{HASIL DAN PEMBAHASAN}

\section{Hasil Penelitian}

Penelitian ini menggunakan model pengembangan ADDIE yang melalui lima tahap, yaitu: Analysis (Analisis), Design (Desain), Development (Pengembangan), Implementation (Implementasi), Evaluation (Evaluasi). Tahap-tahap tersebut dilakukan untuk menciptakan Lembar Kerja Siswa yang valid, praktis, dan efektif pada materi SPLDV untuk siswa kelas VIII. Berikut uraian dari kelima tahap tersebut.

\section{a. Analysis}

Proses pengembangan media ini melalui tahap analisis baik analisis kebutuhan maupun analisis kinerja. Hasil analisis kebutuhan menyimpulkan diperlukannya media yang dapat digunakan membantu siswa belajar materi SPLDV, yaitu Lembar Kerja Siswa. Beberapa penelitian yang sudah mengembangkan Lembar Kerja Siswa diantaranya penelitian Fadilah Sanifatu Salama (2016) dengan judul "Pengembangan Lembar Kerja Siswa Berbantuan Aplikasi Geogebra dengan Pendekatan Penemuan Terbimbing pada Materi Grafik Persamaan Kuadrat di SMA". Penelitian ini adalah jenis penelitian pengembangan yang mengembangkan produk berupa Lembar Kerja Siswa (LKS) berbantuan aplikasi Geogebra dengan model Penemuan Terbimbing pada materi Persamaan Kuadrat di SMA. Penelitian lain yang relevan dengan penelitian ini adalah penelitian yang dilakukan oleh Nur Aini Indah Hermianty (2015) dengan judul "Pengembangan Lembar Kerja Siswa Bercirikan Kontekstual Berbantuan Geogebra pada Materi Persamaan dan Fungsi Kuadrat untuk Siswa Kelas X SMK". Penelitian yang relevan dengan penelitian ini juga dilakukan oleh Dian Andarwati (2013) dengan judul "Pengembangan Lembar Kerja Siswa (LKS) Berbasis Pendekatan Penemuan Terbimbing Berbantuan Geogebra untuk Membelajarkan Topik Trigonometri pada Siswa Kelas X SMA".

Oleh karena media yang akan dikembangkan pada penelitian ini adalah media yang akan digunakan pada materi SPLDV, maka diperlukan analisis terhadap materi ini. Materi SPLDV mencakup indikator yaitu (1) Membedakan sistem persamaan linier dua variabel (SPDLV) dan yang Bukan SPLDV; (2) Menentukan himpunan penyelesaian SPLDV dengan metode grafik; (3) Menentukan himpunan penyelesaian SPLDV dengan metode substitusi; (4) Menentukan himpunan penyelesaian SPLDV dengan metode eliminasi; (5) Menentukan himpunan penyelesaian SPLDV dengan metode gabungan (substitusi dan eliminasi); (6) Menyelesaikan masalah yang berkaitan SPLDV dalam kehidupan sehari-hari. Oleh karena itu dalam mengembangkan media ini perlu memperhatikan cakupan materi tersebut.

\section{b. Design}

Terdapat beberapa hal yang harus didesain untuk menghasilkan media yang diharapkan, yaitu mendesain cover LKS, isi LKS dan tampilan LKS. Media ini didesain agar dapat digunakan dalam pembelajaran baik individu maupun kelompok.

\section{c. Development}

Pada tahap development (pengembangan) ini media diujikan kepada validator. Validator untuk Ahli Materi pada media ini ialah 2 guru yaitu Ibu Rohana Dewi S.Pd, Ibu Siti Musyarofah S.Pd, dan 1 dosen pendidikan matematika yaitu Bp. Tri Nova Hasti Yunianta M.Pd. Ahli materi memberikan penilaian yang terlihat pada Tabel 1 .

TABEL 1

VALIDASI AHLI MATERI

\begin{tabular}{|l|c|l|}
\hline Aspek Penilaian & $\begin{array}{c}\text { Persentase } \\
\text { (\%) }\end{array}$ & Kategori \\
\hline Cakupan Materi & 86.78 & Sangat Baik \\
\hline Kebenaran Materi & 94.44 & Sangat Baik \\
\hline Kontekstual & 87.28 & Sangat Baik \\
\hline Didaktif & 94.21 & Sangat Baik \\
\hline Konstruksi & 94.44 & Sangat Baik \\
\hline Evaluasi Materi & 92.41 & Sangat Baik \\
\hline
\end{tabular}

Validator Ahli Media pada media ini ialah 2 dosen yaitu Bp. Tri Nova Hasti Yunianta M.Pd, Bp. Yustinus M.Pd, dan 1 guru matematika yaitu Ibu Rohana Dewi S.Pd. Ahli media memberikan penilaian yang terlihat pada Tabel 2.

TABEL 2

VALIDASI AHLI MEDIA

\begin{tabular}{lcc}
\hline \multicolumn{1}{c}{$\begin{array}{c}\text { Aspek } \\
\text { Penilaian }\end{array}$} & $\begin{array}{c}\text { Persentas } \\
\text { e(\%) }\end{array}$ & Kategori \\
\hline Didaktik & 91.27 & Sangat Baik \\
Konstruksi & 94.44 & Sangat Baik \\
Komponen LKS & 92.71 & Sangat Baik \\
Kontekstual & 94.21 & Sangat Baik \\
\hline
\end{tabular}

\section{d. Implementation}

Media ini diujicobakan pada 1 kelas di SMP PGRI Banyubiru selama 4 kali pertemuan. Pertemuan pertama untuk melakukan pre test guna mengetahui kemampuan awal siswa. Pertemuan kedua dan ketiga untuk penggunaan LKS dan pertemuan keempat untuk melakukan post test.

Rekapitulasi hasil lembar kepraktisan, uji kepraktisan ini dilakukan oleh 2 guru yaitu Ibu Rohana Dewi S.Pd dan Ibu Siti Musyarofah S.Pd. Validator memberikan saran dan masukan seperti pada Tabel 3 . 
TABEL 3

VALIDASI UJI KEPRAKTISAN

\begin{tabular}{|l|c|c|}
\hline $\begin{array}{c}\text { Aspek } \\
\text { Penilaian }\end{array}$ & $\begin{array}{c}\text { Persentase } \\
\text { (\%) }\end{array}$ & \multicolumn{1}{|c|}{ Kategori } \\
\hline Penggunaan & 85.68 & Sangat Baik \\
\hline Pemeliharaan & 92.57 & Sangat Baik \\
\hline
\end{tabular}

\section{e. Evaluation}

Media ini diujicobakan kepada siswa yang telah mendapatkan materi SPLDV. Sebelum media ini diberikan, siswa terlebih dahulu diberikan tes. Tes ini bertujuan untuk mendapatkan data pre test sebelum diberikan perlakuan. Selanjutnya siswa diberikan kesempatan untuk menggunakan media. Adapun setelah mendapat perlakuan siswa kembali diberikan tes yang bertujuan untuk mendapatkan data post test. Tes yang diberikan terdiri dari 4 soal uraian yang meliputi keenam sub materi dari SPLDV. Soal pre test dan post test memiliki kesamaan dalam tingkat keragaman dan kesulitan soal. Hasil pre test dan post test dapat dilihat pada Tabel 4.

TABEL 4

HASIL PRETEST DAN POSTTEST

\begin{tabular}{|c|c|c|c|c|c|c|}
\hline & \multicolumn{2}{|c|}{ Nilai } & \multirow{2}{*}{$\begin{array}{l}\text { Rata- } \\
\text { Rata }\end{array}$} & \multirow{2}{*}{$\begin{array}{c}\text { Std. } \\
\text { Deviatio } \\
\mathbf{n}\end{array}$} & \multicolumn{2}{|c|}{ Tuntas } \\
\hline & $\operatorname{Max}$ & Min & & & $\mathrm{Jml}$ & $\%$ \\
\hline Pretest & 75 & 12.5 & 4.45 & 21.420 & 1 & 6.25 \\
\hline Posttest & 100 & 62.5 & 76.84 & 20.418 & 14 & 87.5 \\
\hline
\end{tabular}

Siswa dalam kategori (\%)

\begin{tabular}{|l|l|l|l|}
\hline Kurang & Sedang & Tinggi & Sangat Tinggi \\
\hline 12.5 & 46.875 & 31.25 & 9.0125 \\
\hline 6.25 & 9.375 & 31.25 & 53.125 \\
\hline
\end{tabular}

Berdasarkan tabel 4 dapat dilihat bahwa nilai maksimal dan minimum post test lebih tinggi daripada pretest. Terjadi peningkatan yang awalnya hasil rata-rata pre test belum mencapai kriteria ketuntasan minimal menjadi pada post test yang akhirnya mencapai standar ketuntasan minimum. Terdapat peningkatan pula, siswa dalam kategori sedang yang meningkat pada siswa dalam kategori sangat tinggi.

TABEL 5

REKAPITULASI PENDAPAT SISWA TERHADAP MEDIA

\begin{tabular}{|l|c|c|c|c|c|l|}
\hline \multirow{2}{*}{ Indikator } & \multicolumn{5}{|c|}{ Keterangan (\%) } & \multirow{2}{*}{ Ket } \\
\cline { 2 - 6 } & SK & K & C & B & SB & \\
\hline $\begin{array}{l}\text { Kemudahan } \\
\text { dalam } \\
\text { penggunaan LKS }\end{array}$ & & & 11.11 & $\begin{array}{l}41.6 \\
7\end{array}$ & $\begin{array}{l}47 . \\
22\end{array}$ & SB \\
\hline $\begin{array}{l}\text { Peran LKS dalam } \\
\text { menarik minat } \\
\text { untuk belajar. }\end{array}$ & & & 11.11 & $\begin{array}{l}38 . \\
89\end{array}$ & 50 & SB \\
\hline
\end{tabular}

\begin{tabular}{|l|l|l|l|l|l|l|}
\hline $\begin{array}{l}\text { Peran LKS dalam } \\
\text { membantu siswa } \\
\text { belajar secara } \\
\text { mandiri. }\end{array}$ & & & 8.33 & $\begin{array}{l}27.7 \\
8\end{array}$ & $\begin{array}{l}63 \\
.8\end{array}$ & SB \\
9 & & & \\
\hline $\begin{array}{l}\text { Peran LKS dalam } \\
\text { membantu } \\
\text { memahami } \\
\text { materi SPLDV. }\end{array}$ & & $\begin{array}{l}2 . \\
78\end{array}$ & 22.22 & 25 & 50 & SB \\
\hline $\begin{array}{l}\text { Peran LKS dalam } \\
\text { membantu } \\
\text { mengkonstruksi } \\
\text { atau membangun } \\
\text { konsep materi } \\
\text { pembelajaran. }\end{array}$ & & 2. & 5.56 & 33.3 & 58 & SB \\
\hline
\end{tabular}

Keterangan:

$$
\begin{array}{ll}
\text { SB = Sangat Baik } & \text { B = Baik } \\
\text { SK = Sangat Kurang } & \text { C = Cukup } \\
\text { Ket = Keterangan } & \text { K = Kurang }
\end{array}
$$

Guna mengetahui apakah media efektif digunakan untuk pembelajaran SPLDV maka diperlukan uji inferensial. Kedua data merupakan data yang saling berhubungan yang berasal dari 1 kelompok sampel maka uji yang dilakukan adalah uji beda rerata untuk data berkorelasi. Terdapat 2 jenis, uji parametric dengan pair t-test dan uji non parametric dengan wilcoxson. Oleh karena itu dilakukan uji normalitas yang hasilnya dapat dilihat pada Tabel 6.

TABEL 6

UJI NORMALITAS

\begin{tabular}{|l|l|l|l|l|l|l|}
\hline & \multicolumn{3}{|c|}{$\begin{array}{c}\text { Kolmogorov- } \\
\text { Smirnov }\end{array}$} & \multicolumn{3}{c|}{ Shapiro-Wilk } \\
\cline { 2 - 7 } & $\begin{array}{c}\text { Statist } \\
\text { ic }\end{array}$ & Df & Sig. & Statistic & Df & Sig. \\
\hline $\begin{array}{l}\text { Pret } \\
\text { est }\end{array}$ & .109 & 32 & $\begin{array}{l}.20 \\
0\end{array}$ & .962 & 32 & .315 \\
\hline $\begin{array}{l}\text { Post } \\
\text { test }\end{array}$ & .238 & 32 & $\begin{array}{l}.00 \\
0\end{array}$ & .853 & 32 & .000 \\
\hline
\end{tabular}

Uji normalitas yang digunakan adalah kolmogrov-smirnov. Pada tabel tampak bahwa nilai signifikan dari nilai pre test tertulis $.200^{*}$ artinya lebih dari o,2 sedangkan untuk nilai post test tertulis 0.000 artinya mendekati nol yang kurang dari 0,05 . Oleh karena itu dapat disimpulkan bahwa data post test berasal dari populasi yang berdistribusi normal sehingga uji beda rerata yan digunakan adalah uji non parametric dengan uji wilcoxson. Hasil uji ini dapat dilihat pada Tabel 7 . 
TABEL 7

UJI WILCOXSON

Test Statistics ${ }^{\mathrm{a}}$

\begin{tabular}{|l|l|l|}
\hline & & Posttest - Pretest \\
\hline $\begin{array}{l}\text { Z } \\
\begin{array}{l}\text { Asymp. } \\
\text { tailed })\end{array}\end{array} \quad$ Sig. $\quad(2-$ & $-4.845^{\mathrm{b}}$ \\
& .000 \\
\hline
\end{tabular}

a. Wilcoxon Signed Ranks Test

b. Based on negative ranks.

Hasil uji wilcoxson dengan taraf signifikan $\alpha=$ 0,05 pada table 7 tertulis nilai signifikan 0.000 yang artinya nilai signifikan mendekati nol yang kurang dari 0,05 dengan rata-rata nilai post test $(76,84)$ lebih tinggi daripada rata-rata pre test $(51,34)$ maka dapat disimpulkan bahwa media efektif untuk pembelajaran SPLDV.

\section{Pembahasan}

Hasil rekapitulasi validasi ahli materi pada Tabel 1 dan ahli media pada Tabel 2 telah menunjukkan persentase penilaian yang masuk pada kategori sangat baik. Hal ini telah memenuhi indikator kevalidan, sehingga dapat disimpulkan bahwa Lembar Kerja Siswa berbasis kontekstual berbantuan geogebra pada materi SPLDV ini valid. Validator dari ahli materi menilai bahwa media ini sangat cocok digunakan dalam pembelajaran SPLDV. Adapun validator ahli media berpendapat bahwa media ini memiliki tampilan da nisi yang menarik, serta media ini memiliki komponen yang lengkap.

Hasil uji kepraktisan pada Tabel 3 menunjukkan bahwa dari ketiga aspek penilaian satu diantaranya yaitu penggunaan termasuk kategori sangat baik, serta pada aspek pembuatan dan persiapan penggunaan termasuk kategori baik. Hal ini telah memenuhi indikator kepraktisan, sehingga dapat disimpulkan bahwa lembar kerja siswa ini praktis untuk digunakan dalam pembelajaran SPLDV. Guru sebagai pihak yang memberikan penilaian pada uji kepraktisan ini berpendapat bahwa media ini dapat digunakan berulang kali dan melalui media ini menjadikan siswa lebih aktif.

Media ini tidak hanya valid dari ahli materi, ahli media dan tidak hanya praktis untuk digunakan namun juga efektif. Hal ini dapat dilihat pada Tabel 7 dengan uji statistik yang menunjukkan bahwa ada perbedaan yang signifikan dengan rata-rata nilai post test lebih tinggi daripada rata-rata nilai pre test. Oleh karena itu, dapat disimpulkan bahwa Lembar Kerja Siswa ini efektif untuk digunakan pada materi SPLDV. Perbedaan tersebut juga terlihat dengan adanya peningkatan siswa dalam kategori sedang yang meningkat menjadi siswa dalam kategori sangat tinggi. Selain itu, siswa berpendapat bahwa LKS ini sangat menarik dan mempunyai penjelasan yang mudah dimengerti.

\section{PENUTUP}

\section{Simpulan}

Media ini telah dinyatakan valid dari aspek materi dan aspek media pembelajaran dengan persentase berturut-turut 92,59\% dan 92,80\% keduanya termasuk kategori sangat baik. Media ini diujicobakan kepada siswa kelas VIII SMP PGRI Banyubiru dan menghasilkan indeks kepraktisan penggunaan sebesar 75\% termasuk kategori praktis. Uji wilcoxson dengan taraf signifikan $\alpha=0,05$ menghasilkan signifikan mendekati nol yang kurang dari 0,05 dengan rata-rata post test lebih tinggi daripada pre test. Berdasarkan hasil ketiga uji tersebut, maka dapat disimpulkan bahwa Lembar Kerja Siswa Berbasis Kontekstual Berbantuan Software Geogebra pada Materi SPLDV Kelas VIII valid, praktis, dan efektif untuk digunakan.

\section{Saran}

Penelitian pengembangan ini menyarankan bagi guru matematika yang mengajarkan materi SPLDV dapat menggunakan media tersebut. Selain itu diharapkan media ini dapat menginspirasi guru atau peneliti lain untuk berinovasi mengembangkan media pembelajaran lain khususnya LKS.

\section{UCAPAN TERIMA KASIH}

Penulis mengucapkan terimakasih kepada Wasito Hadi, M.Pd., selaku Dekan Fakultas Keguruan dan Ilmu Pendidikan Universitas Kristen Satya Wacana Salatiga yang telah memberikan ijin kepada penulis untuk melakukan penelitian. Novisita Ratu, S.Si., M.Pd., selaku Kepala Program Studi Pendidikan Matematika yang telah memberikan ijin penulis untuk melakukan penelitian. Erlina Prihatnani, S.Si., M.Pd., selaku pembimbing yang dengan kesungguhan meluangkan waktu, tenaga, dan pikiran untuk membimbing, mengarahkan, dan memberikan dorongan sehingga penyusunan skripsi ini berjalan lancar. Bapak dan Ibu Dosen Program Studi Matematika FKIP UKSW yang telah memberikan bekal ilmu pengetahuan dan keterampilan kepada penulis. Kepala SMP PGRI Banyubiru yang telah memberikan ijin untuk melakukan penelitian. Eni Susilawati, S.Pd., selaku guru matematika kelas VIII SMP PGRI Banyubiru yang telah membantu dalam pelaksanaan penelitian. Siswa kelas VIII SMP PGRI Banyubiru yang telah mengikuti kegiatan pembelajaran dengan baik. Bapak dan Ibu yang telah memberikan doa, dukungan, dan motivasi sehingga penulis dapat menyelesaikan studi di Program Studi Pendidikan Matematika FKIP UKSW. Temanteman seperjuangan angkatan 2014 Program Studi Pendidikan Matematika FKIP UKSW yang telah memberikan motivasi dan dukungan serta semua pihak yang telah membantu kelancaran dalam penyusunan skripsi ini, yang tidak bisa penulis sebutkan satu persatu. 


\section{DAFTAR RUJUKAN}

[1] Andarwati, Dian, Pengembangan Lembar Kegiatan Siswa (LKS) Berbasis Pendekatan Penemuan Terbimbing Berbantuan Geogebra untuk Membelajarkan Topik Trigonometri pada Siswa Kelas X SMA, Yogyakarta, 2013.

[2] Ardina, Fimmatur, Lembar Kerja Siswa Berbantuan Geogebra sebagai Upaya Membantu Pemahaman Siswa Materi Limit Fungsi Aljabar, Malang, 2013.

[3] Astuti, Pengembangan Lembar Kerja Siswa (LKS) Berbasis Pendekatan Inkuiri Terbimbing dalam Pembelajaran Kooperatif pada Materi Kalor, Probolinggo, 2013.

[4] Maria, Tarnasia, Pengembangan Pembelajaran Matematika Berbantuan Geogebra dengan Pendekatan Laboratorium untuk Pokok Bahasan Turunan Fungsi di Kelas XI SMA, Madiun, 2002.

[5] Prasepta, Indra, Eksperimentasi Model Pembelajaran Penemuan Terbimbing Berbantuan LKS Komunikatif Ditinjau Dari Gaya Belajar Siswa, Purworejo, 2013.

[6] Prayitno, Heri, Pengembangan Lembar Kerja Siswa (LKS) Matematika SMP Berbantuan Software Geogebra dengan Pendekatan Realistic Mathematics Education (RME) pada Materi Segitiga dan Segiempat Kelas VII SMP Negeri 2 Pucakwangi, Semarang, 2014.

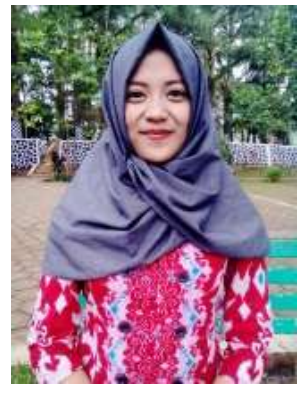

\section{Biografi Penulis Utama}

Lahir di Kabupaten Semarang, 3 Maret 1997. Mahasiswa Pendidikan Matematika Universitas Kristen Satya Wacana Salatiga. Lulus TK Mardi Siwi Kemambang tahun 2002, SD Negeri Kemambang 02 tahun 2008, SMP Negeri 1 Banyubiru tahun 2011 dan SMA Negeri 1 Ambarawa tahun 2014. 